\title{
Estrogen can promote the expression of genes related to precocious puberty in GT1-7 mouse hypothalamic GnRH neuronal cell line via activating $\mathrm{G}$ protein-coupled estrogen receptor
}

\author{
Fang Qian ${ }^{1, *}$, Nian Shi $^{2, *}$ and Huan Zhou $^{3}$ \\ ${ }^{1}$ Department of Eugenics and Genetics, Family Planning Science and Technology Institute, Xinxiang Uygur Autonomous \\ Region, Urumqi, China \\ ${ }^{2}$ Department of Hernia and Abdominal Surgery, The Central Hospital of Wuhan, Tongji Medical College, Huazhong \\ University of Science of Technology, Wuhan, Hubei, China \\ ${ }^{3}$ Department of Neonatology, The Central Hospital of Wuhan, Tongji Medical College, Huazhong University of Science of \\ Technology, Wuhan, Hubei, China
}

\begin{abstract}
The G protein-coupled estrogen receptor (GPER) was proved to be a new type of estrogen receptor (ER). It is unknown that whether estrogen can regulate the secretion of gonadotrophin releasing hormone (GnRH) in GT1-7 cells through the mechanism with the involvement of GPER. The GnRH, estradiol (17 $\beta$-estradiol, E2) and GPER in peripheral blood of precocious puberty children were detected by ELISA and RT-qPCR assays. After E2 treatment, the levels of GPER and GnRH in GT1-7 cells were detected. Following G1 treatment, cell proliferation was examined using a CCK8 assay. The levels of GnRH, KISS1, GPR54, nNOS, c-FOS in GT1-7 cells were assessed following GT1-7 cells were induced by E2 combined with G1 or G15. GnRH, E2 and GPER were significantly increased in precocious puberty children. After E2 treatment, GT1-7 cells expressed more GnRH and GPER was markedly elevated and reached a peak at $8 \mathrm{~h}$. The KISS1, GPR54 and nNOS in GT1-7 cells were significantly increased with G1 induction, but were significantly decreased with G15 induction compared with E2 induction alone. Collectively, GPER cannot promote the release of GnRH via affecting the proliferation of GT1-7 cells, but it may regulate GnRH through KISS1/GPR54 pathway, which provides novel ideas for precocious puberty children treatment.
\end{abstract}

Key words: Precocious puberty - G protein-coupled estrogen receptor — Gonadotrophin releasing hormone - KISS1 - GPR54

\section{Introduction}

Puberty is the culmination of a series of complex developmental events that lead to the acquirement of reproductive capacity and the completion of phenotypic sexual differentiation, defined by the full activation of the so-called hypothalamic-pituitary-gonadal (HPG) axis (or

\footnotetext{
* These authors contributed equally to this work.

Correspondence to: Huan Zhou, The Central Hospital of Wuhan, Tongji Medical College, Huazhong University of Science of Technology, No.26 Shengli Street, Jiangan District, Wuhan, Hubei, 430014, China

E-mail: amyzhouqq123@163.com
}

gonadotropic axis) (Grumbach 2002). In recent years, the influence of exogenous estrogen on adolescent development has attracted increasing attention. A certain amount of exogenous estrogen intake in prepubertal children can cause various types of developmental abnormalities, including precocious puberty, which is more common in girls, presenting as accelerated bone maturation, early healing of long bone epiphyses, early sexual development and early menstruation (Bateman and Patisaul 2008; Brito et al. 2008; Kauffman 2009). Compared with healthy children, precocious puberty children have shorter height in adulthood with uncoordinated body proportion and obesity, which obviously affects the normal growth and development of children (Brito et al. 2008). 
The hypothalamic KISS1 metastasis-suppressor (KISS1) system was identified to be the neuro-hormonal mechanism responsible for puberty onset (Navarro et al. 2007). This hormonal system is driven by the hypothalamic decapeptide gonadotropin-releasing hormone (GnRH), which is episodically released into the hypophyseal portal blood system to activate the pulsatile secretion of luteinizing hormone ( $\mathrm{LH})$, gonadotropins and follicle-stimulating hormone (FSH). These, in turn, operate as major endocrine regulators of the gonads, which reach complete maturity and function at the time of puberty. Therefore, GnRH plays a key role in regulating HPG axis function, which is activated temporarily in late fetal and early infant, and then inhibited in childhood until activated in adolescence again (DiVall and Radovick 2008). This process is regulated by inhibitory or activated hormones, including neuropeptide $\mathrm{Y}$, melatonin, $\mathrm{C}$ aminobutyric acid, kisspeptin, leptin, Galanin, nitric oxide and excitatory amino acids (including glutamate, aspartic acid, etc.) (Rasier et al. 2006), but the regulatory mechanism is still unclear. The hormone estradiol (17 $\beta$-estradiol, E2) is a natural estrogen excreted by human and livestock and is produced primarily within the female ovaries or in the male testes (Tai and Welch 2005). E2 plays a vital role in various physiological processes, with a particular impact on reproductive and sexual function (Wang et al. 2016).

The KISS1 gene product is a RF-amide peptide, and two peptides with structural similarities have recently been shown to play crucial roles in neuroendocrine regulations (Hinuma et al. 1998; Satake et al. 2001). G protein-coupled receptor 54 (GPR54) has been initially identified as an orphan $\mathrm{G}$ protein-coupled receptor with $40 \%$ homology to galanin receptors. Recently, a 54-aa peptide derived from the KISS1 protein was identified as a ligand of GPR54. The effects of kisspeptins were unattainable in GPR54 knockout mice, demonstrating specificity for this receptor (Messager et al. 2005). Activation of GPR54 by KISS1 decreases the cellular motility and proliferation (Kotani et al. 2001; Ohtaki et al. 2001). However, it is unknown whether these features are relevant to the mechanisms leading to PP. Previous research discovered that the disabling mutations in GPR54 caused idiopathic hypogonadotropic hypogonadism, suggesting that kisspeptins are key regulators of reproductive neuroendocrine function (de Roux et al. 2003). Additionally, research have also identified GPR54 and possible KISS1 protein-derived peptide as playing a major and previously unsuspected role in the physiology of the gonadotropic axis (de Roux et al. 2003) and puberty is initiated by the pulsatile release of GnRH (DiVall and Radovick 2008). Although study had indicated that the kisspeptin-GPR54 pathway is an important stimulator of GnRH neuron activity and puberty (Smith and Clarke 2007), factors that affect the kisspeptin-GPR54 pathway have not been determined.
Steroid production subsequently causes the dramatic physical changes associated with puberty (Rasier et al. 2006). Estrogen is a steroid hormone that binds to estrogen receptor (ER) to produce a series of physiological effects. Studies have shown that estrogen can promote GnRH secretion in GT1-7 cells through estrogen receptor-alpha (ER-a), KISS1, GPR54, neuronal nitric oxide synthase (nNOS) and c-FOS (Cheng et al. 2006; Varju et al. 2009). The G protein-coupled estrogen receptor (GPER) has been found to be a new type of estrogen receptor, which can mediate the rapid response and transcriptional regulation of estrogen-like substances by trans-activating the second messenger of epidermal growth factor receptor (EGFR) and $\mathrm{Ca}^{2+}$ (Carmeci et al. 1997; Yu et al. 2012). However, it is unknown whether estrogen can participate in the secretion of GnRH in GT1-7 through the mechanism of GPER. Therefore, the present study aims to explore whether estrogen can stimulate the secretion of $\mathrm{GnRH}$ and the expression of genes related to precocious puberty in GT1-7 through GPER mechanism.

\section{Materials and Methods}

\section{Patient and blood samples}

50 cases of blood samples were obtained from female patients diagnosed with precocious puberty who were admitted to the Central Hospital of Wuhan from June 2017 to December 2018. At the same time, 50 cases of blood samples of healthy children at the same age were collected as controls. Blood samples (each $5 \mathrm{ml}$ ) were harvested in serum separation tubes. After separation, the serum was stored at $-80^{\circ} \mathrm{C}$ until analysis by enzyme linked immunosorbent assay (ELISA). All the study and protocols have been approved by the Ethics Committee of the Central Hospital of Wuhan (License NO. 2019-17). Signed informed consent was obtained from all people tested.

\section{Cell culture and treatment}

The mouse GnRH-producing hypothalamic cell line GT1-7 cells (p16) were cultured as a monolayer in complete fresh Dulbecco's modified Eagle's medium (DMEM; Sigma-Aldrich; Merck KGaA, Darmstadt, Germany) supplemented with $10 \%(\mathrm{v} / \mathrm{v})$ fetal bovine serum (FBS) and $1 \%$ penicillinstreptomycin. The cultures were incubated at $37^{\circ} \mathrm{C}$ in a humidified atmosphere containing $5 \% \mathrm{CO}_{2}$ for 2 days after seeding. Then, cells were washed with PBS twice and digested with $0.25 \%$ trypsin-EDTA. When more than half of the cells were observed to become round under a microscope, a serum-containing medium was added to terminate digestion. After made into single-cell suspension, cells were cultured in an incubator and inoculated into a 12-well plate 
after cell passage for three times. After cell growth reaching about $80-90 \%$, the complete cell culture medium was replaced with serum-free medium and GT1-7 cells were incubated with water-soluble $17 \beta$-estradiol (E2, $100 \mathrm{pmol} / \mathrm{l}$, Sigma) or G1 ( $1 \mu \mathrm{m})$ for $4,8,12$ and $16 \mathrm{~h}$, respectively. After detection and screening, GT1-7 cells were incubated with E2 $(100 \mathrm{pmol} / \mathrm{l})$ for $8 \mathrm{~h}$, and then treated with $\mathrm{G} 1(1 \mu \mathrm{m})$ or GPER antagonist $(\mathrm{G} 15,100 \mathrm{~nm})$ for $24 \mathrm{~h}$.

\section{Enzyme-linked immunosorbent assay (ELISA)}

Serum was stored at $-80{ }^{\circ} \mathrm{C}$ until analysis for GnRH, E2 and GPER using ELISA kit purchased from Shanghai Bogu Biotechnology Co., Ltd. (Shanghai, China) according to the manufacturer's instructions. Following GT1-7 cells were treated with estradiol (E2, $100 \mathrm{pmol} / \mathrm{l})$ for 4, 8, 12 and $16 \mathrm{~h}$, an ELISA kit of GnRH (R\&D Systems, Minneapolis, MN, USA) were used to quantify the level of GnRH in the GT1-7 cells medium. The cells were divided into five groups: Control, E2-4 h, E2-8 h, E2-12 h and E2-16 h groups.

\section{Immunofluorescence staining}

GT1-7 cells were seeded at $10 \%$ confluence onto small glass coverslips placed in 24-well plates. Twelve hours later, different treatments were performed and then the coverslips were removed, washed with PBS three times, and fixed with 4\% paraformaldehyde in PBS for $20 \mathrm{~min}$. After pushing through the cytomembrane $(0.1 \%$ Triton, $0.1 \%$ sodium citrate for $10 \mathrm{~min}$ ) and blocking in 5\% goat serum for $1 \mathrm{~h}$, the cells were incubated with GPER primary antibodies at $4^{\circ} \mathrm{C}$ overnight. After washing with PBS, the cells were incubated with a 1:500 dilution of a fluorescent tag (Alexa Fluor 488; Thermo Fisher Scientific) and conjugated with secondary antibodies for $30 \mathrm{~min}$ in the dark. Next, the cells were treated with DAPI (1:10,000, Invitrogen) for 5 min, washed with PBST, covered with an antifade mounting medium, and placed onto microscope slides. Finally, the location of GPER was measured using a laser scanning microscope equipped with a digital camera (Q Imaging, Burnaby, BC, Canada). Photographs were taken with $400 \times$ magnification. Experimental grouping: Control, E2-4 h, E2-8 h, E2-12 h and E2-16 h groups.

\section{CCK-8 assay}

GT1-7 cells were seeded in 96-well plates. GT1-7 cells were treated with GPER agonists $(\mathrm{G} 1,1 \mu \mathrm{m} / \mathrm{ml})$. The cells were cultured at $37^{\circ} \mathrm{C}, 5 \% \mathrm{CO}_{2}$ for the indicated times $(4,8,12$ and $16 \mathrm{~h}$ ) and then treated with $10 \mu \mathrm{l}$ of CCK-8 solution (Dojindo Molecular Technologies, Gaithers burg, MD, USA) at the indicated times. Subsequently, the cells were cultured for another $3 \mathrm{~h}$. The amount of formazan dye generated by cellular dehydrogenase activity was measured by absorbance at $450 \mathrm{~nm}$ with a microplate reader (Enspire Multimode Plate Reader, PerkinElmer, USA). Experimental grouping: Control, G1-4 h, G1-8 h, G1-12 h and G1-16 h groups.

\section{Quantitative real-time polymerase chain reaction ( $R T$ - $q P C R$ )}

GnRH, E2, GPER, KISS1, GPR54, nNOS and c-FOS expression was analyzed using an RT-PCR system (Bio-Rad, Marnes-la-Coquette, France). TRIzol reagent (Thermo Fisher Scientific) was used according to the manufacturer's instructions. Total RNA was extracted from serum sample and GT1-7 cells using TRIzol Reagent. For the investigated genes, mRNA expression was normalized to that of GAPDH. The qPCR reaction was performed following: $95^{\circ} \mathrm{C}$ for $2 \mathrm{~min}$, followed by 40 cycles of $15 \mathrm{~s}$ at $95^{\circ} \mathrm{C}$ and at $60^{\circ} \mathrm{C}$ for $1 \mathrm{~min}$. The primers are described in Table 1 . Relative gene expression was calculated using the $2^{-\Delta \Delta \mathrm{Ct}}$ method.

\section{Western blotting}

Total proteins from treated cells were washed with cold phosphate-buffered saline and extracted using RIPA lysis buffer (Cell Signaling Technology). The protein concentrations in the cell lysates were conducted using a BCA protein assay reagent (Pierce, Rockfold, IL, USA). Cell proteins ( $45 \mu \mathrm{g}$ ) were separated by sodium dodecyl sulphate polyacrylamide gel electrophoresis (SDS-PAGE) and then transferred onto polyvinylidene fluoride membranes (PVDF, Sigma-Aldrich,

Table 1. Primers used for quantitative polymerase chain reaction

\begin{tabular}{lll}
\hline Gene & Forward primer $\left(5^{\prime}\right.$-3’' $^{\prime}$ & Reverse primer $\left(5^{\prime}\right.$-3’') $^{\prime}$ \\
\hline GnRH & ACTGTGTGTTTGGAAGGCTG C & TTCCAGAGCTCCTCGCAGATC \\
E2 & ATCCCAGAGCTTCAAAGTGTATG & GTCCCTACTACATTCACGTCCAG \\
KISS1 & ATGATCTCGCTGGCTTCTTGGCA & AGTTCCAGTTGTAGGTGGACAGGT \\
$c-F O S$ & GGCAAAGTAGAGCAGCTATCTCCT & CATCTCGGAGAATACGGTCGT \\
GPR54 & GGTGCTGGGAGACTTCATGT & AGTGGCACATGTGGCTTG \\
$n N O S$ & GGCCACCAATGAGAAAGAGA & TATTCCTGAAGCCCCTTGC \\
GAPDH & ATCATCCCTGCCTCTACTGG & GTCAGGTCCACCACTGACAC \\
\hline
\end{tabular}



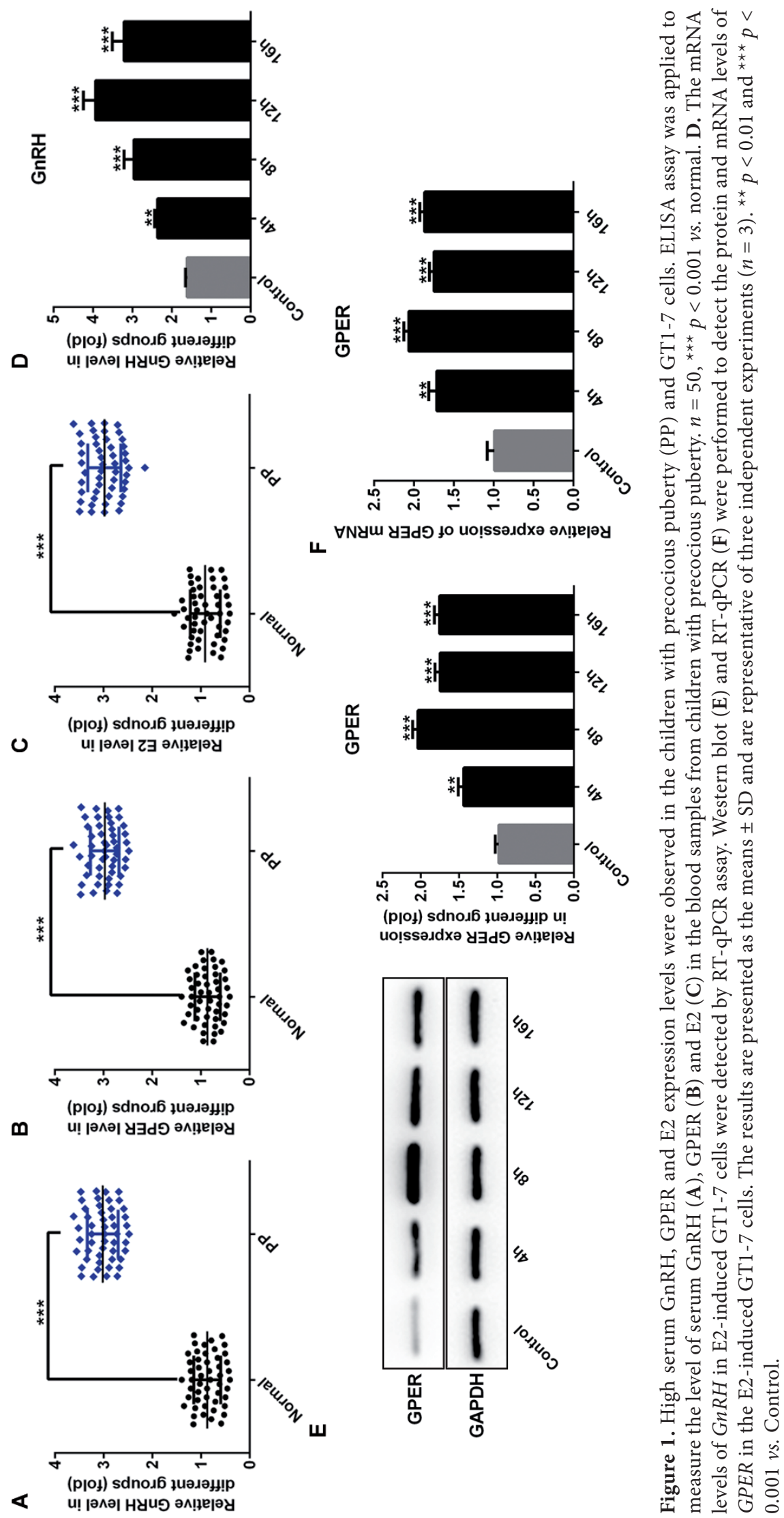
Corp., Cambridge, UK). After the membranes had been blocked with $5 \%$ bovine serum albumin for $1 \mathrm{~h}$ at room temperature, the blots were probed overnight at $4^{\circ} \mathrm{C}$ with the primary antibodies against GPER, CDK2, Cyclin E, p27, GnRH, KISS1, GPR54, nNOS and c-FOS (Cell Signaling Technology). Subsequently, the membranes were washed with Tris-buffered saline plus Tween20 (TBST) and incubated with the secondary antibodies conjugated to HRP (Cell Signaling Technology) for $1 \mathrm{~h}$ at room temperature. After washing twice with TBST, the signals were visualized with an enhanced chemiluminescence detection kit (Amersham Pharmacia Biotech, Piscataway, NJ). The images were analyzed using the software program Image Gauge (LAS1000plus, Fujifilm, Tokyo, Japan). The relative amount of proteins was normalized to GAPDH.

\section{Statistical analysis}

Data from $\geq 3$ independent experiments were presented as means \pm SD and were analyzed by one-way analysis of variance. Comparison between the groups was performed with post hoc Tukey's test. Statistical analyses were performed using SPSS for Windows software (version 19.0; IBM Corp., Armonk, NY, USA). A $p<0.05$ was considered to indicate statistically significant difference.

\section{Results}

Expression of GnRH, GPER and E2 in the serum of children with precocious puberty

ELISA and RT-qPCR were employed to observe the levels of $G n R H, E 2$ and GPER in the serum of children with or without PP. The results suggested that the levels of $G n R H, E 2$ and GPER in the serum of children with precocious puberty had become elevated compared with the levels in the normal healthy children (Fig. 1A-C, $p<0.001$ ). Next, whether E2 can activate GPER to promote $\mathrm{GnRH}$ secretion in vitro using GT1-7 cells was explored.

\section{Effects of E2 on GnRH and GPER expression in GT1-7 cells}

ELISA was adopted to evaluate the expression of $\mathrm{GnRH}$ in GT1-7 cells followed ectogenic (E2)-induced for 4, 8, 12 and $16 \mathrm{~h}$. Comparing to the Control group, the secretion of $\mathrm{GnRH}$ in the $\mathrm{E} 2$ groups was elevated significantly in the time-dependent manner but reached a peak at $12 \mathrm{~h}$ (Fig. $1 \mathrm{C}, p<0.001)$. At 4, 8, 12 and $16 \mathrm{~h}$ following E2 treatment, the protein and mRNA levels of GPER in GT1-7 cells were significantly increased compared with the Control group and reached a peak at $8 \mathrm{~h}$ (Fig. $1 \mathrm{E}$ and F, $p<0.001$ ). Immunofluorescence staining was performed to detect the protein expression and distribution of GPER and the positive staining (Green) was observed in the cytoplasm, mainly concentrated in the perinuclear region and cell membrane with a highest fluorescence intensity at $8 \mathrm{~h}$ compared to control (Fig. 2, $p<0.001$ ), and these results were consistent with the above-mentioned protein and mRNA levels. Since GPER is an estrogen receptor, we selected the E2 treatment time ( $8 \mathrm{~h}$ ) at the highest expression level for the following experiment.

\section{Effects of GPER agonist on the proliferation of GT1-7 cells}

A CCK-8 assay was applied to measure the proliferation of GT1-7 following induction with GPER agonist (G1) for 4, 8, 12 and $16 \mathrm{~h}$. As demonstrated in Fig. 3A, the proliferation activity of GT1-7 cells had no significance at four time points compared with the control group $(p>0.05)$. Western blot analysis was performed to additionally examine the mechanism of G1-induced proliferation of GT1-7 cells. It has been established an increase of the CDK2, Cyclin E and p27 expressions leads to cell proliferation and cell cycle progression (Rodier et al. 2001; Coqueret 2003; Ventura et al. 2017). In the present study, there was no significant difference in the CDK2, Cyclin E and p27 protein levels at 4, 8, 12 and 16 h compared with the Control group (Fig. 3B and $\mathrm{C}, p>0.05)$.

Effects of GPER agonist or antagonist on the expression of KISS1, c-FOS, GPR54 and nNOS in GT1-7 cells

To additionally evaluate whether the potential molecular mechanism of GPER on the release of GnRH in GT1-7 cells via the KISS1/GPR54 signaling pathway, Western blot and RT-qPCR were conducted with the purpose of detecting the protein and mRNA expressions of GPR54, KISS1, nNOS and $c$-FOS in GT1-7 cells treated with GPER agonist (G1) or antagonist (G15). Before the experiment began, the GT1-7 cells were divided into the following groups: Control group (GT1-7 cells with no treatment), the E2 group (GT1-7 cells treated with E2 for $8 \mathrm{~h}$ ), the E2+G1 group (GT1-7 cells treated with E2 for $8 \mathrm{~h}$ following G1 for $24 \mathrm{~h}$ ), the E2+G15 group (GT1-7 cells treated with E2 for $8 \mathrm{~h}$ following G15 for $24 \mathrm{~h})$. The Western blot and RT-qPCR demonstrated the upregulated KISS1, GPR54 and nNOS expressions (Fig. 4A and $\mathrm{B}, p<0.001)$ and unaffected expression of $c$-FOS in GT1-7 cells in the E2 group compared with the Control group $(p>$ 0.05). G1-treatment following E2-treatment of GT1-7 cells increased the mRNA levels of KISS1, GPR54 and nNOS significantly compared to E2 group $(p<0.05)$. Additionally, there was a significant reduce in the expression of KISS1, GPR54 and $n N O S$ in the E2+G15 group compared with the E2 group $(p<0.01)$, but they were higher than the Control group. However, the level of $c$-FOS is not affected by G1 or $\mathrm{G} 15$, and there is no significant change all the time. 


\section{Discussion}

In the present study, we have identified that the E2-regulated GPER signaling pathway regulated the release of GnRH and related molecular in the GT1-7 cells. This information may give us an insight to the E2-dependent changes that also characterizes the relevant genes for precocious puberty in vivo across the estrus cycle. Beyond this aspect, the results also provide a critically important reference for further research and intervention treatment of childhood sexual precocity.

Periodic changes in serum E2 levels across the reproductive cycle of female rodents exert both negative and positive feedback effects on the secretion of the two gonadotropins, LH and FSH from the anterior pituitary. The onset of puberty begins with an increase in GnRH to activate the HPG axis (Navarro et al. 2007). E2 quantification is an indicator of human sexual maturation status and helps doctors diagnose diseases associated with sex hormone imbalances. Increased E2 production is largely responsible for breast development, genital growth, and changes in the distribution of body fat in pubescent girls. At the same time, $\mathrm{GnRH}$ was known to promote the secretion of $\mathrm{LH}$ and $\mathrm{FSH}$, thus promoting the maturation of the gonad and the production of a large number of sex hormones. The pattern of GnRH fluctuation in this compartment correlates with pulsatile GnRH secretion into the hypophysial portal system and LH secretion (Skinner et al. 1997). Our results demonstrated that $G n R H, E 2$ and GPER expressions were upregulated in children with precocious puberty (Fig. 1), which suggests that sex hormones, including estrogen, do play a regulatory role in the development of early puberty in children.

In view of the expression patterns of $G n R H, E 2$ and GPER in blood samples of precocious children, we will continue to explore their relevant mechanisms in GT1-7 cells. Estrogen hormones, as feedback signals, report the functional gonadal status to the brain and play key roles in the control of mammalian reproduction, which has been well established (Herbison et al. 2001). In the present study, we detected the expressions

A
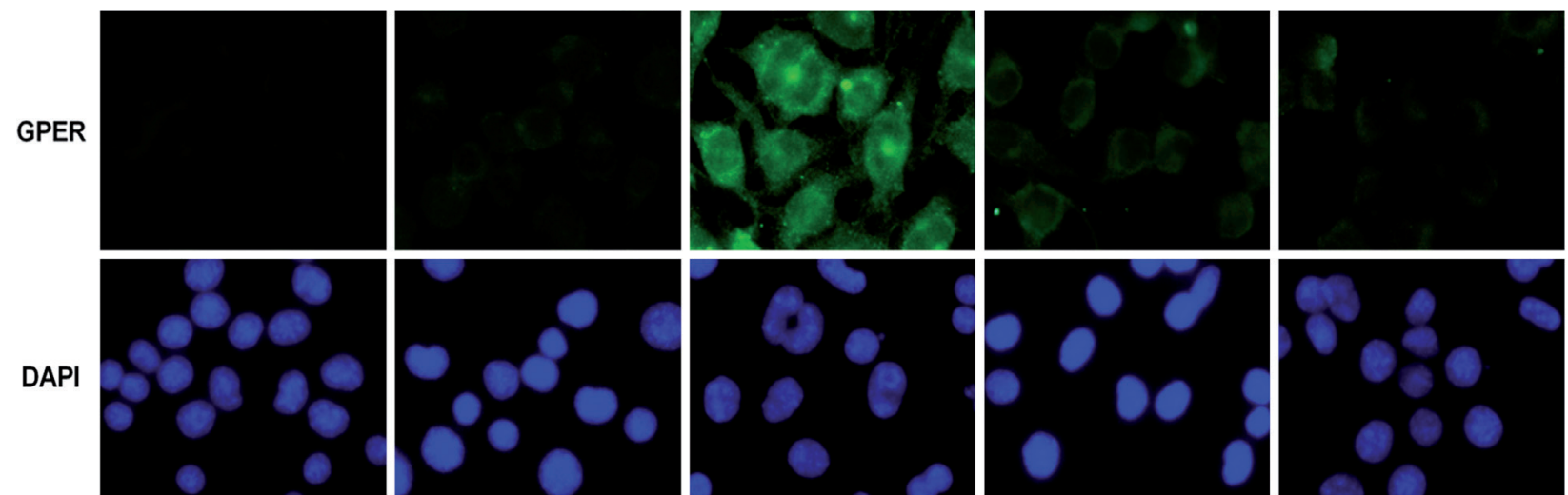

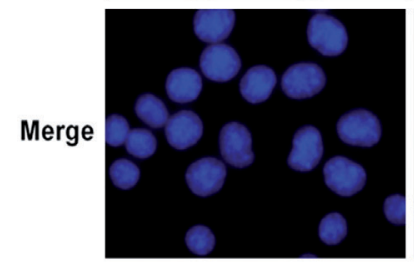

Control

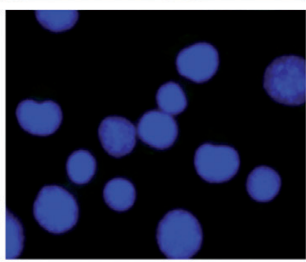

$4 \mathrm{~h}$

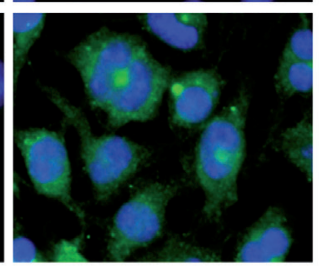

8h

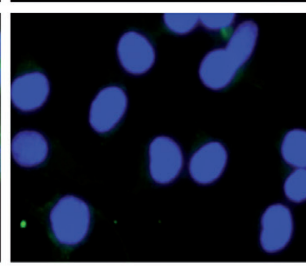

$12 \mathrm{~h}$

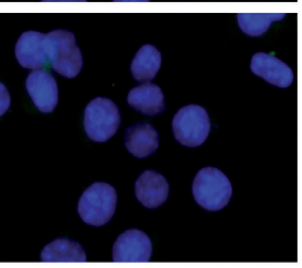

$16 \mathrm{~h}$

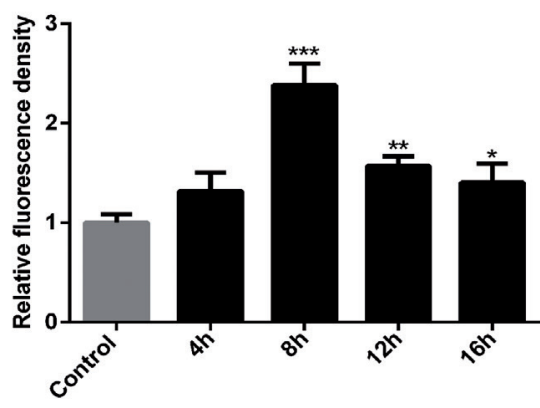

Figure 2. Immunofluorescence analysis of the GPER expression in the GT1-7 cells induced by E2. At 4, 8, 12 and $16 \mathrm{~h}$ following E2 (100 pmol/l) treatment, the perinuclear and plasma membrane expression of GPER in GT1-7 cells was analyzed by immunofluorescence staining. A. Green fluorescence represents the expression of GPER in GT1-7 cells (magnification $\times 400$ ). B. Statistical analysis of relative fluorescence density of GPER expressions. The results are presented as the means $\pm \mathrm{SD}$ and are representative of three independent experiments $(n=3)$. ${ }^{\star} p<0.05,{ }^{* *} p<0.01$ and ${ }^{* * *} p<0.001$ vs. Control. 

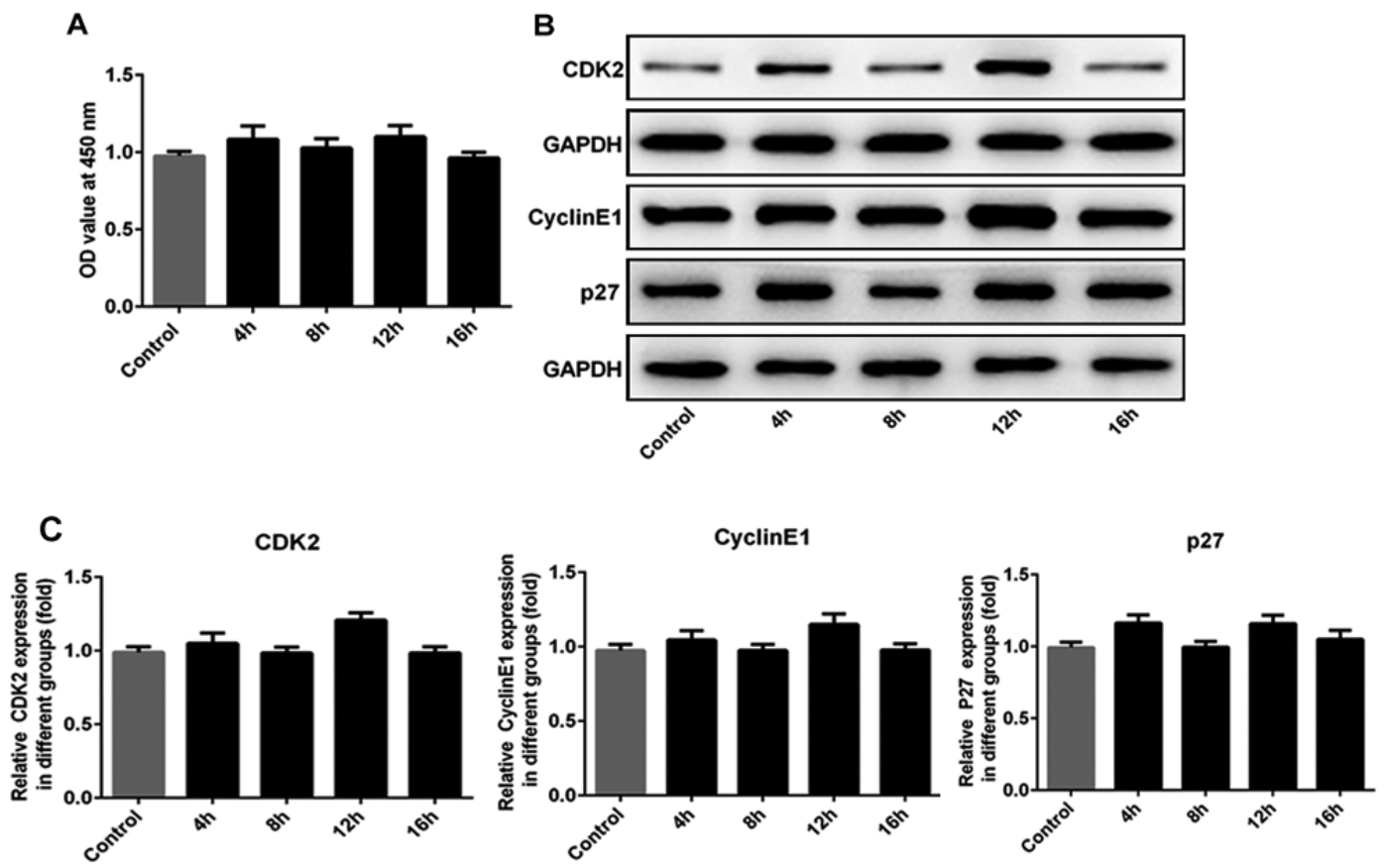

Figure 3. Effects of GPER agonist (G1) on cell proliferation of GT1-7 cells and the CDK2, Cyclin E1 and p27 expressions. A. MTT assay was conducted to determine cell proliferation of GT1-7 cells after treated without or with G1 for 4, 8, 12 and 16 h. B. Representative pictures of Western blot for CDK2, Cyclin E and p27 expressions in GT1-7 cells after treated without or with G1 for 4, 8, 12 and 16 h. C. Statistical analysis of CDK2, Cyclin E and p27 expressions $(n=3) . p>0.05$ vs. Control.

of GnRH and GPER in GT1-7 cells induced by exogenous estrogen (E2), and the effect of G1 on cell proliferation. Data from GT1-7 cells indicate that estrogen and intracellular cAMP-levels are involved in the regulation of endogenous circadian clock mechanism, possibly through the opening of cyclic nucleotide gated channels (CNGs) expressed by GnRH neurons, in vitro (Blackman et al. 2007). The increased levels of AMPA receptor subunits in E2-treated GT1-7 cells might result in enhanced $\mathrm{Ca}^{2+}$-permeability, suggesting that these receptors play regulatory roles in LHRH neurosecretion. We have identified that many E2-regulated genes were associated with specific cellular pathways including cellular signaling, cellular movement, cellular growth and development, immune response, and inflammatory disease.

We found that E2-treatment remarkably increased the GnRH and GPER expressions in the GT1-7 cells and the GPER predominantly expressed in cytoplasm and cell membrane of GT1-7 cells, while the E2 processing times that these two genes expressed the most were different, one $8 \mathrm{~h}$ and the other $12 \mathrm{~h}$ (Fig. 2). This phenomenon may be caused by periodic changes of sex hormones. It is known that estrogen is one of the most important stimuli to induce mammary cell proliferation. Furthermore, estrogenic action is responsible for G1-S progression through the cell cycle (Castoria et al. 2012). However, GPER agonists (G1)-treat- ment had no significant effect on cell proliferation. Moreover, we evaluated CDK2, cyclin E, and p27 expressions, which were not found altered by G1 at any concentration assessed (Fig. 3). The results indicate that estrogen can increase the secretion of GPER, but GPER does not regulate the expression of $\mathrm{GnRH}$ by affecting the cell proliferation process. It is likely that there are still other signaling pathways in which GPER is involved and can regulate the expression of $\mathrm{GnRH}$, thus playing a role in the process of childhood sexual precocity, like the KISS1/GPR54 signaling pathway.

A previous study had shown that kisspeptin-10 augments GnRH-stimulated FSH was released from male rat pituitary explants in vitro (Navarro et al. 2005). KISS1 gene was initially cloned as a tumor metastasis suppressor gene (Lee et al. 1996), and the mature protein was named metastin confirming that it controlled the migration of trophoblast cells (Janneau et al. 2002). KISS1 mRNA is mainly present in the placenta and brain (Muir et al. 2001). Thereafter, in the brain, KISS1 has been localized to the hypothalamus and basal ganglia. GPR54 was cloned in humans (called hOT7T175 or Axor-12) and found to be expressed mainly in the brain, pituitary, and placenta. Experiments have established that GPR54 was a protein involved in the regulation of gonadotropin secretion (de Roux et al. 2003). GPR54 and possibly KISS1 protein-derived peptide, playing a major role in the physiology of the gonadotropic axis, by which 
the loss of GPR54 function impairs pubertal development and reproductive functions (de Roux et al. 2003). Nitric oxide (NO), one of the key retrograde signaling molecules, is produced partly by the neuronal NO-synthase (nNOS) enzyme in the nervous system. It has been demonstrated that neuronal damage is associated with excessive NO synthesis due to the increasing activity and expression of nNOS, and erectile dysfunction by inhibiting NO synthase activity (Geronimo-Olvera et al. 2018). The structure of c-FOS is highly conserved in humans. In most cell types, c-FOS protein levels are relatively low under basal conditions. The signals associated with neuronal excitation also can elicit transient c-FOS expression, e.g. voltage-dependent $\mathrm{Ca}^{2+}$ channel activation and neurotransmitters (Greenberg et al. 1986). There have been hundreds of reports investigating c-FOS expression in the central nervous system (CNS)
(Herrera and Robertson 1996). Some investigators have used c-FOS expression as a tool to study neuronal populations that are activated after different stimuli and c-FOS is also required for repression of $\mathrm{GnRH}$. What's more, the presence of c-FOS protein within LHRH neurons is often indicative of neuronal activation (Herbison 1998). In the female rat, the expression of FOS in A2 cell appears to vary with the changes of estrous cycle, so the largest numbers of these cells expressed FOS at proestrus, which are periodical (Krukoff 1993). E2-application to GT1-7 cells also induced c-FOS and c-Myc transcription factors (Varju et al. 2009). In the present study, KISS1, GPR54 and nNOS involved in regulation of GnRH were also found to be regulated by E2. Both Western blot and RT-qPCR revealed a marked elevation in the transcript level after $8 \mathrm{~h}$ of E2-treatment (Fig. 4). However, overexpression of GPER could promote the expression

A
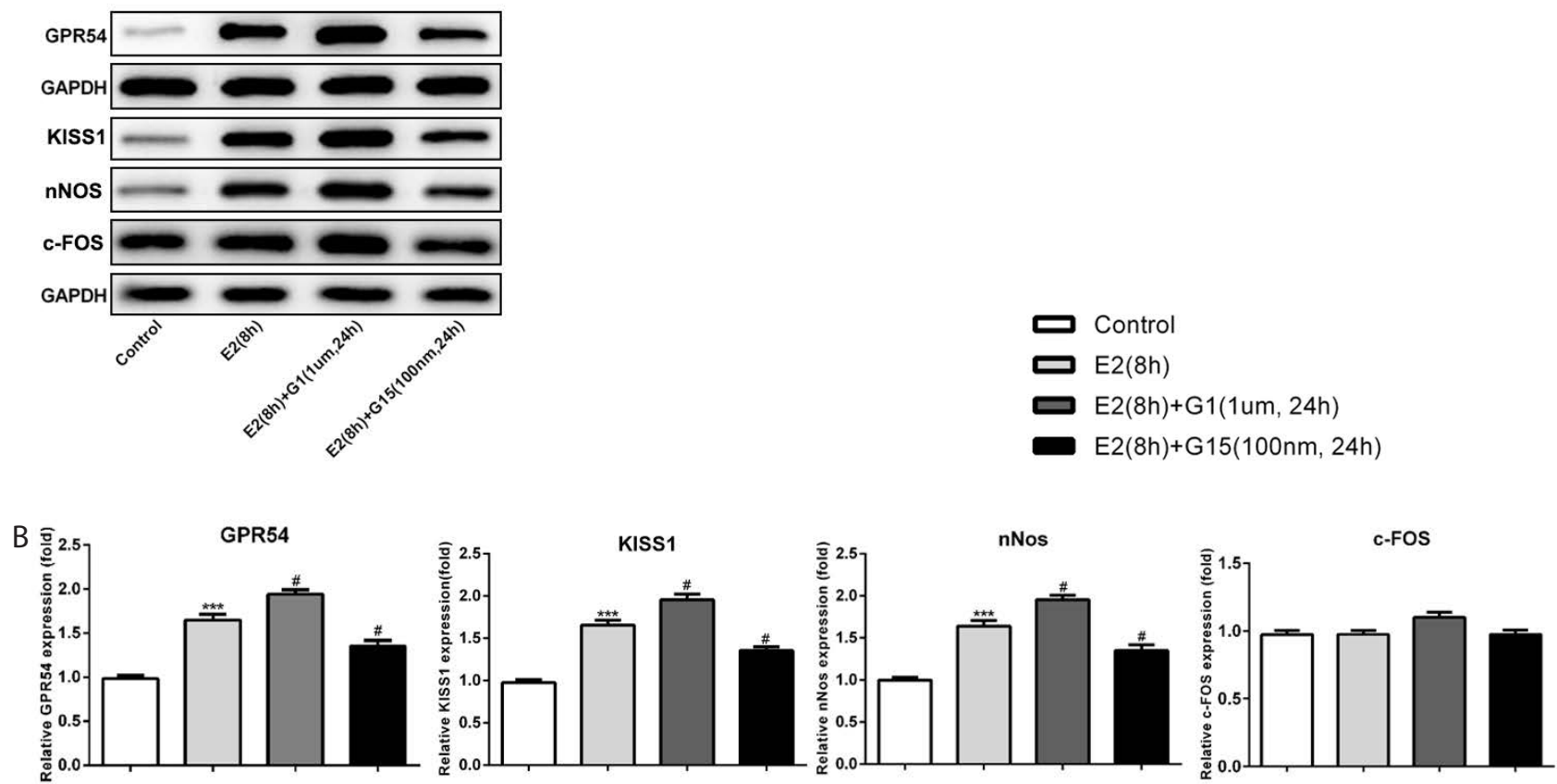

C
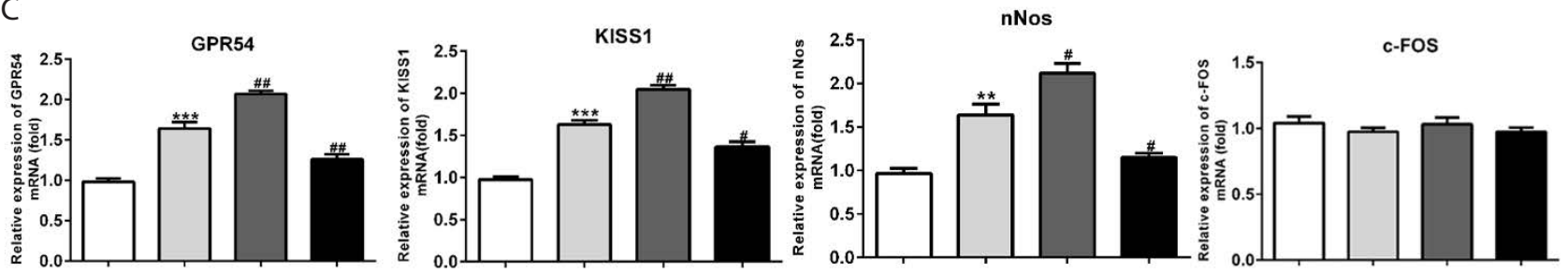

Figure 4. Effects of GPER agonist or antagonist on GPR54, KISS1, nNOS and c-FOS expression in GT1-7 cells. A. Representative pictures of Western blot to detect the expressions of GPR54, KISS1, nNOS and c-FOS in E2-induced GT1-7 cells after treated with GPER agonist (G1) or antagonist (G15) for $24 \mathrm{~h}$. B. All these results were statistical analyzed from Western blot in A. C. The mRNA levels of GPR54, KISS1, $n N O S$ and $c$-FOS were tested using RT-qPCR. The results are presented as means \pm SD and are representative of three independent experiments $(n=3) .{ }^{* *} p<0.01$ and ${ }^{* * *} p<0.001$ vs. Control; ${ }^{\#} p<0.05,{ }^{\# \#} p<0.01$ vs. E2 (8 h) group. 
of E2-induced KISS1, GPR54, nNOS and c-FOS to increase again in the GT1-7 cells. Conversely, knockdown of GPER reversed the E2-induced increase in expressions of KISS1, GPR54, nNOS and c-FOS, but did not completely return to normal (Fig. 4). These results indicated that in the presence of estrogen, GPER may regulate the secretion of GnRH through the KISS1/GPR54 signaling pathway, which just provides a theoretical basis for the intervention of the secretion of $\mathrm{GnRH}$ to treat children with precocious puberty.

The current evidence revealed that estrogen regulated GnRH secretion through the KISS1/GPR54 signaling pathway only in vitro and the specific mechanism of its effect in vivo needs further more studies. In addition, there may be other factors participating in the effect of estrogen on precocious puberty, which needs to be demonstrated by further studies in the future.

\section{Conclusion}

In summary, the results of our study explored the related genes of precocious puberty and regulatory pathways through which E2 influences the cellular functions of GT1-7 cells. The novel observations are supposed to laid a foundation for further elucidating the in vivo studies of estrogen-regulated signaling pathway of $\mathrm{GnRH}$ secretion, and provides a new idea to study the molecular mechanism and clinical treatment of early childhood puberty.

Conflict of interest. The authors declare no conflict of interest.

\section{References}

Bateman HL, Patisaul HB (2008): Disrupted female reproductive physiology following neonatal exposure to phytoestrogens or estrogen specific ligands is associated with decreased $\mathrm{GnRH}$ activation and kisspeptin fiber density in the hypothalamus. Neurotoxicology 29, 988-997

https://doi.org/10.1016/j.neuro.2008.06.008

Blackman BE, Yoshida H, Paruthiyil S, Weiner RI (2007): Frequency of intrinsic pulsatile gonadotropin-releasing hormone secretion is regulated by the expression of cyclic nucleotide-gated channels in GT1 cells. Endocrinology 148, 3299-3306 https://doi.org/10.1210/en.2006-1427

Brito VN, Latronico AC, Arnhold IJ, Mendonca BB (2008): Update on the etiology, diagnosis and therapeutic management of sexual precocity. Arq. Bra. Endocrinol. Metabol. 52, 18-31 https://doi.org/10.1590/S0004-27302008000100005

Carmeci C, Thompson DA, Ring HZ, Francke U, Weigel RJ (1997): Identification of a gene (GPR30): with homology to the G-protein-coupled receptor superfamily associated with estrogen receptor expression in breast cancer. Genomics 45, 607-617

https://doi.org/10.1006/geno.1997.4972
Castoria G, Giovannelli P, Lombardi M, De Rosa C, Giraldi T, de Falco A, Barone MV, Abbondanza C, Migliaccio A, Auricchio F (2012): Tyrosine phosphorylation of estradiol receptor by Src regulates its hormone-dependent nuclear export and cell cycle progression in breast cancer cells. Oncogene 31, 4868-4877

https://doi.org/10.1038/onc.2011.642

Cheng AS, Jin VX, Fan M, Smith LT, Liyanarachchi S, Yan PS, Leu YW, Chan MW, Plass C, Nephew KP, et al. (2006): Combinatorial analysis of transcription factor partners reveals recruitment of c-MYC to estrogen receptor-alpha responsive promoters. Mol. Cell 21, 393-404

https://doi.org/10.1016/j.molcel.2005.12.016

Coqueret O (2003): New roles for p21 and p27 cell-cycle inhibitors, a function for each cell compartment? Trends Cell Biol. 13, 65-70 https://doi.org/10.1016/S0962-8924(02)00043-0

de Roux N, Genin E, Carel JC, Matsuda F, Chaussain JL, Milgrom E (2003): Hypogonadotropic hypogonadism due to loss of function of the KiSS1-derived peptide receptor GPR54. Proc. Natl. Acad. Sci. USA 100, 10972-10976 https://doi.org/10.1073/pnas.1834399100

DiVall SA, Radovick S (2008): Pubertal development and menarche Ann. N. Y. Acad. Sci. 1135, 19-28 https://doi.org/10.1196/annals.1429.026

Gerónimo-Olvera C, Tristán-López L, Martínez-Lazcano JC, García-Lara L, Sánchez-Mendoza A, Morales-Martínez A, Hernández-Melesio MA, Arregui L, Ríos C, Pérez-Severiano F (2018): Striatal protection in nNOS knock-out mice after quinolinic acid-induced oxidative damage. Neurochem. Res. 44, 421-427 https://doi.org/10.1007/s11064-018-2688-3

Greenberg ME, Ziff EB, Greene LA (1986): Stimulation of neuronal acetylcholine receptors induces rapid gene transcription. Science 234, 80-83 https://doi.org/10.1126/science.3749894

Grumbach MM (2002): The neuroendocrinology of human puberty revisited. Horm. Res. 57, 2-14 https://doi.org/10.1159/000058094

Herbison AE (1998): Multimodal influence of estrogen upon gonadotropin-releasing hormone neurons. Endocr. Rev. 19, 302-330 https://doi.org/10.1210/edrv.19.3.0332

Herbison AE, Pape J-R, Simonian SX, Skynner MJ, Sim JA (2001): Molecular and cellular properties of $\mathrm{GnRH}$ neurons revealed through transgenics in the mouse. Mol. Cell. Endocrinol. 185, 185-194 https://doi.org/10.1016/S0303-7207(01)00618-9

Herrera DG, Robertson HA (1996): Activation of c-fos in the brain. Prog. Neurobiol. 50, 83-107 https://doi.org/10.1016/S0301-0082(96)00021-4

Hinuma S, Habata Y, Fujii R, Kawamata Y, Hosoya M, Fukusumi S, Kitada C, Masuo Y, Asano T, Matsumoto H, et al. (1998): A prolactin-releasing peptide in the brain. Nature 393, 272-276 https://doi.org/10.1038/30515

Janneau JL, Maldonado-Estrada J, Tachdjian G, Miran I, Motté N, Saulnier P, Sabourin JC, Coté JF, Simon B, Frydman R, et al. (2002): Transcriptional expression of genes involved in cell 
invasion and migration by normal and tumoral trophoblast cells. J. Clin. Endocrinol. Metab. 87, 5336-5339

https://doi.org/10.1210/jc.2002-021093

Kauffman AS (2009): Sexual differentiation and the Kiss1 system, hormonal and developmental considerations. Peptides 30, 83-93 https://doi.org/10.1016/j.peptides.2008.06.014

Kotani M, Detheux M, Vandenbogaerde A, Communi D, Vanderwinden JM, Le Poul E, Brézillon S, Tyldesley R, Suarez-Huerta N, Vandeput F, et al. (2001): The metastasis suppressor gene KiSS-1 encodes kisspeptins, the natural ligands of the orphan G protein-coupled receptor GPR54. J. Biol. Chem. 276, 3463134636

https://doi.org/10.1074/jbc.M104847200

Krukoff TL (1993): Expression of c-fos in studies of central autonomic and sensory systems. Mol. Neurobiol. 7, 247-263 https://doi.org/10.1007/BF02769178

Lee JH, Miele ME, Hicks DJ, Phillips KK, Trent JM, Weissman BE, Welch DR (1996): KiSS-1, a novel human malignant melanoma metastasis-suppressor gene. J. Natl. Cancer Inst. 88, 1731-1737 https://doi.org/10.1093/jnci/88.23.1731

Messager S, Chatzidaki EE, Ma D, Hendrick AG, Zahn D, Dixon J, Thresher RR, Malinge I, Lomet D, Carlton MB, et al. (2005): Kisspeptin directly stimulates gonadotropin-releasing hormone release via $G$ protein-coupled receptor 54 . Proc. Natl. Acad. Sci. USA 102, 1761-1766 https://doi.org/10.1073/pnas.0409330102

Muir AI, Chamberlain L, Elshourbagy NA, Michalovich D, Moore DJ, Calamari A, Szekeres PG, Sarau HM, Chambers JK, Murdock P, et al. (2001): AXOR12, a novel human G proteincoupled receptor, activated by the peptide KiSS-1. J. Biol. Chem. 276, 28969-28975 https://doi.org/10.1074/jbc.M102743200

Navarro VM, Castellano JM, Fernández-Fernández R, Tovar S, Roa J, Mayen A, Barreiro ML, Casanueva FF, Aguilar E, Dieguez C, et al. (2005): Effects of KiSS-1 peptide, the natural ligand of GPR54, on follicle-stimulating hormone secretion in the rat. Endocrinology 146, 1689-1697 https://doi.org/10.1210/en.2004-1353

Navarro VM, Castellano JM, Garcia-Galiano D, Tena-Sempere M (2007): Neuroendocrine factors in the initiation of puberty, the emergent role of kisspeptin. Rev. Endocr. Metab. Disord. 8, $11-20$ https://doi.org/10.1007/s11154-007-9028-2

Ohtaki T, Shintani Y, Honda S, Matsumoto H, Hori A, Kanehashi K, Terao Y, Kumano S, Takatsu Y, Masuda Y, et al. (2001): Metastasis suppressor gene KiSS-1 encodes peptide ligand of a G-protein-coupled receptor. Nature 411, 613-617 https://doi.org/10.1038/35079135

Rasier G, Toppari J, Parent AS, Bourguignon JP (2006): Female sexual maturation and reproduction after prepubertal exposure to estrogens and endocrine disrupting chemicals, a review of rodent and human data. Mol. Cell. Endocrinol. 254-255, 187-201 https://doi.org/10.1016/j.mce.2006.04.002

Rodier G, Montagnoli A, Di Marcotullio L, Coulombe P, Draetta GF, Pagano M, Meloche S (2001): p27 cytoplasmic localization is regulated by phosphorylation on Ser10 and is not a prerequisite for its proteolysis. EMBO J. 20, 6672-6682 https://doi.org/10.1093/emboj/20.23.6672

Satake H, Hisada M, Kawada T, Minakata H, Ukena K, Tsutsui $\mathrm{K}$ (2001): Characterization of a cDNA encoding a novel avian hypothalamic neuropeptide exerting an inhibitory effect on gonadotropin release. Biochem. J. 354, 379-385 https://doi.org/10.1042/bj3540379

Skinner DC, Caraty A, Malpaux B, Evans NP (1997): Simultaneous measurement of gonadotropin-releasing hormone in the third ventricular cerebrospinal fluid and hypophyseal portal blood of the ewe. Endocrinology 138, 4699-4704 https://doi.org/10.1210/endo.138.11.5494

Smith JT, Clarke IJ (2007): Kisspeptin expression in the brain, catalyst for the initiation of puberty. Rev. Endocri. Metab. Disord. 8, 1-9 https://doi.org/10.1007/s11154-007-9026-4

Tai SS, Welch MJ (2005): Development and evaluation of a reference measurement procedure for the determination of estradiol-17beta in human serum using isotope-dilution liquid chromatography-tandem mass spectrometry. Anal. Chem. 77, 6359-6363 https://doi.org/10.1021/ac050837i

Varju P, Chang KC, Hrabovszky E, Merchenthaler I, Liposits Z (2009): Temporal profile of estrogen-dependent gene expression in LHRH-producing GT1-7 cells. Neurochem. Int. $\mathbf{5 4}, 119-134$ https://doi.org/10.1016/j.neuint.2008.11.003

Ventura C, Nunez M, Gaido V, Pontillo C, Miret N, Randi A, Cocca C (2017): Hexachlorobenzene alters cell cycle by regulating p27-cyclin E-CDK2 and c-Src-p27 protein complexes. Toxicol. Lett. 270, 72-79

https://doi.org/10.1016/j.toxlet.2017.02.013

Wang R, Chon H, Lee S, Cheng Z, Hong SH, Yoon YH, Choo J (2016): Highly sensitive detection of hormone estradiol E2 using surface-enhanced Raman scattering based immunoassays for the clinical diagnosis of precocious puberty. ACS Appl. Mater. Interfaces 8, 10665-10672

https://doi.org/10.1021/acsami.5b10996

Yu FX, Zhao B, Panupinthu N, Jewell JL, Lian I, Wang LH, Zhao J, Yuan H, Tumaneng K, Li H, et al. (2012): Regulation of the Hippo-YAP pathway by G-protein-coupled receptor signaling. Cell 150, 780-791 https://doi.org/10.1016/j.cell.2012.06.037

Received: September 3, 2019

Final version accepted: November 2, 2019 